\title{
The anaesthetist and the head-injured patient
}

The anaesthetists ' contribution to the management of head-injured patients has expanded considerably in the past few years, reflecting change in the total management of these patients. The anaesthetist now has vital responsibilities in the immediate care of the patient in the emergency room, the radiology department, during surgical interventions, and in the critical care unit. This has occurred through an increasing appreciation of the fact that secondary changes, which are superimposed on the initial cerebral insult, have major impact on the outcome of head-injured patients. If the patient reaches hospital alive then theoretically, treatment or prevention of the secondary injury should prevent death. Recent evidence suggests that mortality can be reduced without significantly increasing the number of people surviving in a vegetative or severely disabled state. ${ }^{1}$

In a revicw of avoidable factors in the deaths of head-injured patients who talked after the injury, 26 per cent had an airway obstruction, 22 per cent had hypotension. (primarily intraoperative), and 17 per cent had poorly controlled seizures. ${ }^{2}$ The anaesthetist has the technical skills and the knowledge of physiology and pharmacology to make a major contribution to the well being of these patients.

Head injuries are a major cause of death among people under the age of 30 years and result in more than 200,000 potential years of lost life in Canada each year. ${ }^{3}$ Thirty-five per cent of patients with head injuries will have extracranial injuries as well ${ }^{4}$ It is in this group that the anaesthetist needs to be most vigilant. With all energies focused on organs other than the brain, it is easy to lose sight of the fact that it is the extent of the brain injury that, in most instances, becomes the factor limiting a return to normal life.

What is the pathophysiology of a head injury? A head injury may involve the scalp, skull, dura, blood vessels, brain, spine and spinal cord. Al-
A.W. Gelb MB CHB FRCP(C) P.H. Manninen MD FRCP(C), B.J. Mezon MD fRCP(C), R.J. Lee MB FRCP(C), Q.J. Durward MB CHB though injuries to the scalp and skull may not be of major consequence to the brain, they serve as indicators that the head has been traumatized. A skull fracture occurs in only about 65 per cent of patients with a severe injury to the brain. ${ }^{5}$

The major consequence of any head injury is the injury to the brain. Brain injury occurs in two phases. At the instant of impact, a variable amount of primary brain injury occurs. Then, secondary processes are set in motion which lead to further brain injury and often death. At the present time, we only have preventative and not therapeutic measures for primary brain injury. All our therapy is directed at the secondary insult.

Experiments with animals subjected to blunt head injury have demonstrated that rotatory movements of the brain inside the head produce shearing stresses which are responsible for the most significant brain injuries. These stresses are most apparent at the interfaces between structures of different densities. Mild injuries tend to involve only the cortex while progressively more severe injuries involve the deeper structures including the brain stem. Thus, injury to the brain stem is uncommon without diffuse injury to the hemispheres. ${ }^{6}$

The brain may be injured in different ways at the moment of impact. ${ }^{7}$ These include concussion, contusion, laceration, petechial haemorrhages and white matter lesions. Concussion is a clinical syndrome of loss of consciousness without focal signs, and is completely reversible within 24 hours. It was believed until recently that no permanent brain injury occurred with concussion. However,

From the Departments of Anaesthesia and Neurosurgery, University of Western Ontario, London, Ont.

Address correspondence to: Dr. A.W. Gelb, Depanment of Anaesthesia, University Hospital, P.O. Box 5339, Station "A", London, Ontario, Canada, N6A 5 A5. 
microglial cell clusters, indicating cell damage, have been demonstrated in patients with recent concussion who died of other causes. ${ }^{8}$ Other nonobservable changes such as nerve fibre stretching, alterations in membrane polarity, and disruption of synapses have been postulated in the pathogenesis of concussion. Even the mildest of injuries may thus be associated with brain damage that differs only quantitatively from more severe injuries.

Contusions indicate more severe brain damage. They appear grossly as haemorrhagic and necrotic areas which commence at the crest of the gyri in the superficial cortex and extend into the brain substance. As the brain rotates inside the skull after the impact, it rubs against the rough areas of the floor of the anterior and middle fossae, and the spheniod wings. Consequently, the inferior and anterior temporal lobes and the inferior frontal lobes are usually most affected by contusions. These lesions are often on the side opposite the impact (contrecoup lesions), and occur most frequently with blows to the occipital region. Contusions can also be seen under the site of impact on the skull, particularly if there is a depressed skull fracture. Lacerations of the brain occur in similar sites to contusions, but represent a more severe injury.

Petechial haemorrhages developing in the white matter and corpus callosum are caused by tearing of blood vessels during brain rotation. These haemorrhages may produce damage by their coalescence into haematomas, or by producing ischaemia distal to the torn yessel. The same shearing forces which tear blood vesscls also tear nerve fibres producing diffuse white matter damage. ${ }^{6}$ These lesions are most frequently responsible for the persistent vegetative state.

Further brain injury may result from haematoma formation, cerebral oedema, and cerebral ischaemia. A haematoma may be extradural (ruptured meningeal vessels associated with a fracture), subdural (often associated with severe brain contusion and/or laceration) or it may be intracerebral ("pulped" temporal lobe). Many patients with an extradural haematoma do not have a severe primary brain injury and, therefore, have a lucid interval before deteriorating. Evacuation of the clot before secondary brain damage occurs should result in a good outcome. In contrast, subdural and intracerebral haematomas usually occur in people with a severe primary brain injury. The final outcome is frequently poor despite evacuation of the haematoma.

Normally, the amount of extracellular fluid in the brain (less than $150 \mathrm{ml}$ ) is tightly controlled by an intact blood-brain barrier. "Vasogenic" cerebral oedema results when intravascular fluid leaks across a disrupted blood-brain barrier into the extracellular space. In addition, swelling of cells injured by trauma and ischaemia leads to "cytotoxic" brain oedema. This combined volume of fluid produces brain swelling which may behave as a mass.

\section{What factors influence intracranial pressure?}

The intracranial space may be regarded as a rigid container of almost constant volume consisting of brain ( 80 per cent), blood ( 10 per cent) and cerebral spinal fluid (CSF) (10 per cent). In order that intracranial pressure (ICP) remains normal $(<15$ $\mathrm{mmHg}$ ), an increase in the volume of one constituent must be compensated for by a reduction in the volume of the other constituents. Initially, CSF is displaced out of the cranium into the spinal canal where the lumbar dural sac is distensible and can hold extra fluid, and its rate of absorption is increased. Next, blood is displaced from intracranial veins and sinuses into the jugular veins and spinal epidural veins. Lastly, the brain is shifted away from the mass either from one side to the other, or from one compartment to the other through the tentorial notch. These mechanisms work well initially and the ICP changes very little. Eventually, these compensatory mechanisms fail (Figure 1). This leads to one or both of the following consequences - rapid elevation of the ICP and/or squeezing of the unci (medial temporal lobes) into the tentorial hiatus with resultant compression of the third nerves and brain stem, and stretching of the posterior cerebral arteries. This phenomenon is called transtentorial herniation and is responsible for the classic signs of deterioration from a supratentorial mass, viz., deteriorating level of consciousness, a dilating ipsilateral pupil, hemiparesis or decerebration, hyperventilation, hypertension and bradycardia. Pathological changes developing as a consequence of transtentorial herniation include haemorrhage into the third nerves, pressure necrosis of the uncus and parahippocampal gyrus by the tentorial edge, and occlusion of the posterior cerebral artery producing haemorthagic infarction of the occipital lobe. When there is severe side to 


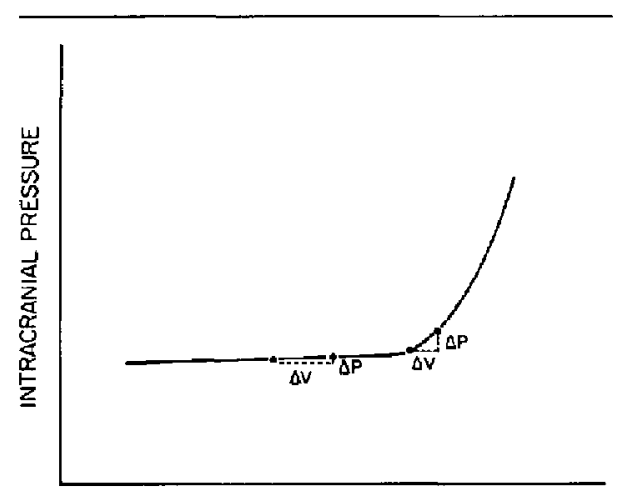

INTRACRANIAL VOLUME

FIGURE 1 Intracranial pressure volume curve. Relatively large changes in volume result in small changes in pressure on the horizontal part of the curve. When no further compensation is possible, relatively small changes in volume result in large increases in pressure.

side brain shift, herniation of the cingulate gyrus under the falx may occur. With posterior fossa masses, hemiation of the cerebellar tonsils through the foramen magnum may occur leading to medullary compression and early respiratory arrest.

The clinical importance of ICP is twofold. First, the cerebral perfusion pressure (CPP) which is the difference between the mean arterial pressure and the ICP is altered. As ICP rises and/or blood pressure falls, a critical point is reached at which ischaemia is produced. In general, CPP should be kept greater than $60 \mathrm{mmHg}$. Secondly, as the ICP rises due to a mass, the brain shifts as a means of compensation for the volume change and the detrimental effects described in the above section take place.

In head trauma, intracranial volume is most commonly increased by haematoma or oedema formation. ICP may be reduced by removing the clot, by reducing oedema fluid with mannitol, furosemide and possibly steriods, or by external drainage of CSF. The factors most easily manipulated by the anaesthetist are those that change cerebral blood flow (CBF) and intracranial blood volume. $\mathrm{CBF}$ is linearly related to the arterial $\mathrm{PCO}_{2}$ over the range of $20-80 \mathrm{mmHg}$ increasing $1-2 \mathrm{ml}$ per $100 \mathrm{gm}$ per minute for each $\mathrm{mmHg}$ change in $\mathrm{CO}_{2}$ tension (Figure 2). ${ }^{9,10}$ Autoregulation normally keeps CBF remarkably constant between the

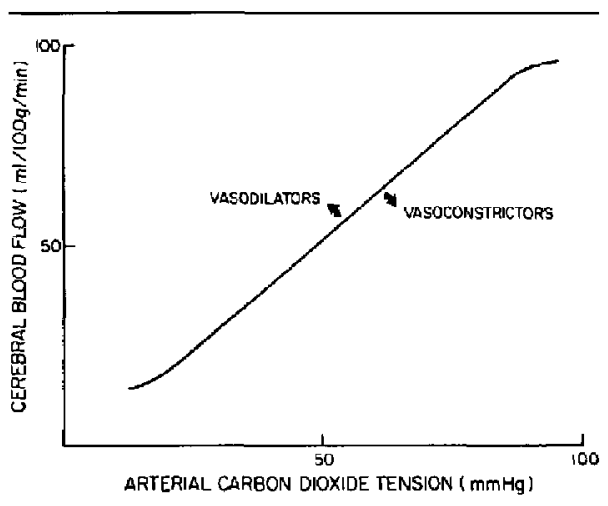

FIGURE 2 Increases in $\mathrm{PaCO}_{2}$ from $20-80$ mmHg causes a linear increase in cerebral blood flow. Cerebral vasodilators such as halothane, shift the curre to the left and stcepen the slope. Vasoconstrictors, such as thiopentone shift the curve to the right and reduce the slope.

mean arterial pressures (MAP) of $50-150 \mathrm{mmHg}$ (Figure 3 ). ${ }^{\text {II }}$ Outside of this pressure range, flow is directly related to pressure. In hypertensive patients, both the upper and lower limits of autoregulation are shifted to higher pressures. ${ }^{12}$ With changes in oxygen tension, CBF is relatively unchanged until the $\mathrm{PaO}_{2}$ drops below 60 when a dramatic increase accurs.

Regional impairment of autoregulation is relatively common in the first week after a severe injury. ${ }^{13,14}$ In these areas, CBF will vary passively with the CPP (or MAP). Thus pressures that are normally associated with unchanged $C B F$ may result in critical ischaemia or dramatic increases in ICP. Blood pressure should therefore be kept within the patient's normal range. Regional impairment of $\mathrm{CO}_{2}$ rcactivity may also occur, even after mild trauma. ${ }^{13,15}$ Despite this, hyperventilation has salutary effects on raised ICP by reducing blood volume and therefore intracranial volume in the regions with normal reactivity. The induced alkalosis helps to combat the regional acidosis which is responsible for the dysautoregulation and loss of $\mathrm{CO}_{2}$ reactivity.

Rises in cerebral venous pressure (CVP) will also elevate ICP. The venous outflow may be obstructed by poor positioning of the head during surgery. A reminder about this from the anaesthetist to the intent surgeon may dramatically improve intracranial dynamics. A Trendelenberg or head down 
position should be strenuously avoided. Any increase in intrathoracic pressure may be transmitted to the head. Thus coughing, straining and high levels of PEEP ( $>10 \mathrm{~cm} \mathrm{H} \mathrm{H}_{2} \mathrm{O}$ ) should be avoided.

\section{What is the effect of the drugs I use?}

\section{Sedatives and anticonvulsants}

Sedative drugs are used to decrease activity and excitation and for anxiolysis. Sedatives should be used with extreme caution in patients with a head injury as they may alter the neurological state, obscure the neurological signs and result in respiratory depression.

(a) Benzodiazepines are the most popular and widely used. Diazepam produces a depression of cerebral metabolic rate $\left(\mathrm{CMRO}_{2}\right)$ and $\mathrm{CBF}$ in patients with diffuse brain damage. ${ }^{16}$ Cardiovascular and respiratory effects are minimal with small doses but larger doses may cause depression. Diazepam is an effective anticonvulsant.

(b) Droperidol, a butyrophenone, produces sedation, is antiemetic, and blocks adrenergic activity. The combination of droperidol with fentanyl is used frequently in anaesthesia. This combination reduces CBF and $\mathrm{CMRO}_{2} .{ }^{17}$ Droperidol is a long acting drug ( 12 hours) and may produce mental disturbances.

(c) Phenothiazines - chlorpromazine produces alpha-adrenergic blockade resulting in a decrease in blood pressure, depresses the cough reflex and hiccoughs, dries secretions, and promotes heat loss.

(d) Dilantin exerts an antiepileptic activity without causing significant depression of the central nervous system. Animal data suggests that dilantin may improve neurological outcome after global ischaemia possibly due to a membrane stabilizing effect. ${ }^{18}$ Caution is required with intravenous use as hypotension, depression of myocardial contractility and depression of the S-A node may result. Intravenous doses should not exceed $50 \mathrm{mg} \cdot \mathrm{min}^{-1}$.

\section{Narcotics}

Opiate drugs are used to produce pain relief, sedation, and euphoria. The drugs interact with stereospecific receptor binding sites in the brain and other tissues to produce pain relief.

The central nervous system effects of opiates, in addition to analgesia, include drowsiness, changes in mood, and mental clouding. They produce

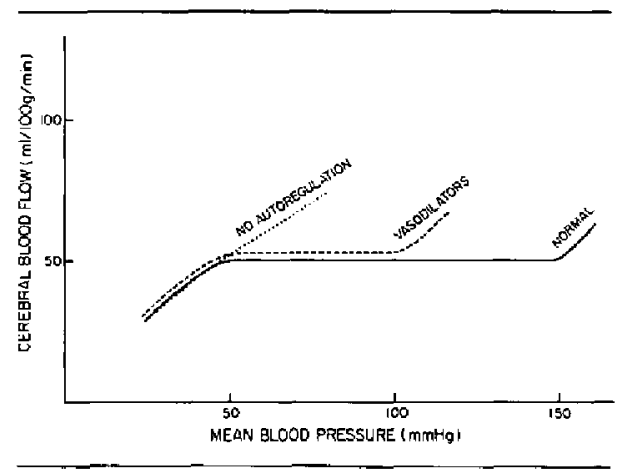

FIGURE 3 Intact autoregulation keeps cerebral blood flow constant when the cerebral perfusion pressure is varied from 50-150 munHg. Cerebral vasodilaturs, such as halothane, increase cerebral blood flow and shoren the pressure range over which autoregulation is maintained. If autorgulation is defecrive, cerebral blood flow varies linearly with, and passively follows, perfusion pressure

constriction of the pupil due to an excitatory action on the parasympathetic segment of the third nerve nucleus. Opiates cause a small decrease in $\mathrm{CMRO}_{2}$ and $\mathrm{CBF} .{ }^{17.19}$ However, like other sedatives, they may increase ICP due to increases in $\mathrm{PCO}_{2}$ from respiratory depression. Cardiovascular stability may be affected, especially after sudden changes in position, by peripheral arteriolar and venous dilation through release of histamine and central suppression of adrenergic tone.

(a) Codeine is the most commonly used narcotic in neurosurgical patients. Codeine is effective against moderate pain and produces little sedative effects, which is important in the clinical evaluation of the neurological status of the patient.

(b) Fentanyl is currently a very popular agent. Fentanyl decreases heart rate which may result in a decrease in blood pressure. Though fentanyl is a short acting drug, with increased doses (more than 300 micrograms) actions of the drug may persist for hours.

(c) Naloxone is a narcotic antagonist which reverses sedation and often analgesia. With availablity of this drug, one can be a bit more liberal with the use of narcotic analgesics. There has been much recent interest in the use of megadoses $\left(1 \mathrm{mg} \cdot \mathrm{kg}^{-1}\right)$ in the treatment of focal cerebral ischaemia. ${ }^{20} \mathrm{~A}$ definitive benefit has not been shown and data on its use in head injuries is lacking. 
Intravenous anaesthetic agents

(a) Barbiturates: Barbiturates in anaesthetic doses produce a decrease in $\mathrm{CMRO}_{2}$ and $\mathrm{CBF}$ of about 50 per cent from control. ${ }^{17}$ The decrease in $\mathrm{CMRO}_{2}$ appears to be related to a decrease in metabolic oxygen requirements. The reduced $\mathrm{CBF}$ results in a decreased ICP which is beneficial to the patient with intracranial hypertension. Sleep doses of barbiturates, however, may have catastrophic effects on the cardiovascular system if given as a large, rapid bolus to the hypovolemic patient. Methohexatone, in addition, may induce seizures in susceptible individuals and should probably be avoided.

Considerable controversy surrounds the use of high dose barbiturates for brain protection. ${ }^{21} \mathrm{Barbi}-$ turate coma may offer protection to the injured brain by a number of mechanisms: decreased $\mathrm{CMRO}_{2}$ and ICP, redistribution of $C B F$, decreased oedema formation, free radical scavenging or control of post-injury seizure activity (see ICU section).

(b) Alfathesin: Alfathesin markedly reduces $\mathrm{CMRO}_{2}$ and ICP and reduces the effect of endotracheal intubation on ICP in patients with nomal and increased ICP. ${ }^{22,23}$ Alfathesin depresses respiration and cardiac output similarly to thiopentone. Its major disadvantage is the high frequency of hypersensitivity reactions thought to be due to the solvent used.

(c) Ketamine: Ketamine produces unconsciousness and analgesia. Its main effect on the central nervous system seems to be to disorganize rather than to depress it. It produces an increase in CBF and ICP but, in man, global $\mathrm{CMRO}_{2}$ is unchanged. ${ }^{24}$ Ketamine stimulates the cardiovascular system increasing blood pressure and heart rate. An important difficulty with ketamine is in the recovery phase. It is slow, with nausea and vomiting, delirium, excitement, and hallucinations frequently occurring. It is a dangerous drug for the headinjured patient.

(d) Lidocaine: Lidocaine is a potent local anaesthetic used both topically and intravenously. It is an effective cough suppressant and prevents marked increases in blood pressure and heart rate when given before endotracheal intubation. Lidocaine causes a decrease in $\mathrm{CMRO}_{2}$ and $\mathrm{CBF}$. This decrease in CBF during intubation will attenuate increases in ICP. Intravenous lidocaine $1-1.5 \mathrm{mg}$. $\mathrm{kg}^{-1}$ is more effective than topically applied lidocaine. ${ }^{25}$ Lidocaine is as effective as thiopentone for the rapid reduction of intraoperative intracranial hypertension but causes less cardiovascular depression. ${ }^{26}$ Lidocaine, therefore, would be safer in patients with marginal circulatory function.

\section{Inhalation agents}

In general, inhalational anaesthetics at anaesthetic concentrations decrease $\mathrm{CMRO}_{2}$ by $10-30$ per cent. ${ }^{17,27}$ The exception is nitrous oxide which causes a small increase. All these agents increase CBF by $30-100$ per cent at anaesthetic concentrations. Thus, the inhalational agents appear to uncouple the regulation of CBF from its normal metabolic control. In situations where the normal buffering mechanisms of ICP have been exceeded, this increase in CBF can produce intracranial hypertension. The increase in CBF can, in most cases, be prevented by moderate hyperventilation prior to the introduction of the inhalational agent. ${ }^{28,29}$ The effects of the inhalational agents on the cardiovascular and respiratory systems can impair intracranial dynamics further. Systemic arterial hypotension, particularly in the face of elevated ICP, can reduce CPP. The respiratory depression secondary to these drugs can cause increased $\mathrm{PCO}_{2}$ in spontaneously breathing patients and lead to increases in ICP.

\section{Muscle relaxants}

(a) Succinylcholine: The question of increases in ICP in response to succinylcholine is debatable. Transient increases in ICP have been found, but in patients who require rapid airway control, succinylcholine given after thiopentone can be used with little expectation of a large increase in ICP. ${ }^{30}$ With an unstable cervical spine, fasciculations may result in spinal cord damage. These can be attenuated by prior usage of a small dose $\left(0.04 \mathrm{mg} \cdot \mathrm{kg}^{-1}\right)$ of d-tubocurarine.

(b) d-tubocurarine: A major adverse effect of this drug is the production of hypotension from histamine release and ganglionic blockade. Cerebral effects include an increased ICP due to cerebral vasodilatation. With a decrease in BP there may also be a decrease in CPP.

(c) Pancuronium: The adverse effect of this drug is the increase in heart rate and blood pressure which may result in increased ICP. It is less likely if the drug is given slowly. This drug is currently the preferred nondepolarizing muscle relaxant. 


\section{Diuretics}

(a) Osmotic diuretics: Their use in head-injured patients is to reduce ICP and possibly to improve tissue perfusion. Mannitol is the agent most extensively used. An initial dose of $1 \mathrm{gm} \cdot \mathrm{kg}^{-1}$ is given over ten minutes, the result being evident within 15-20 minutes. A second dose may be needed and thereafter doses of $0.25 \mathrm{gm} \cdot \mathrm{kg}^{-1}$ are usually adequate. Large doses will increase intravascular volume and cardiac output. Therefore caution must be used in patients with compromised myocardial function. If given frequently or continuously, it may lead to an increased serum osmolality, electrolyte imbalance, and a rebound increase in ICP.

(b) Loop Diuretics: Diuretics such as furosemide may be used in addition to an osmotic agent to promote diuresis and to reduce the amount of cerebral oedema. ${ }^{31}$ By diuresis-mediated brain dehydration, reduced cerebrospinal fluid formation and a reduction of cerebral oedema, the loop diuretics are able to decrease ICP without raising intravascular volume.

\section{Steroids}

The use of steroids in the head-injured patient remains controversial ${ }^{32,33}$ Steroids are effective in combating cerebral oedema in patients with focal chronic lesions such as brain tumours. There is less evidence of benefit in acute widespread lesions and in post-hypoxic damage. Despite this, steroids continue to be used in many head-injured patients.

\section{Vasoactive agents}

Vasoactive agents can influence the central nervous system either by a direct action on cerebral vascular tone or by an indirect action via their effect on the systemic circulation.

(a) Pressor agents: If the blood-brain barrier is intact, these agents usually act indirectly through effects on the systemic circulation. Drugs such as norepinephrine, epinephrine, isoproterenol, angiotensin and dopamine may increase CBF by their effect on systemic blood pressure or by increasing $\mathrm{CMRO}_{2}$ if they are cerebral stimulants. ${ }^{17}$ If administered in the face of hypotension, CBF may be restored to nommal because of an increase in CPP. If hypertension is produced, CBF and ICP may increase dangerously high especially in those individuals with deranged autoregulation. A direct cerebral vasoconstrictive effect of these agents is not seen probably because of the overriding local metabolic control of cerebral vascular tone.

(b) Vasodilators: Vasodilators may influence cerebral perfusion indirectly by producing systemic hypotension and thus decreasing CPP. However, commonly used direct vascular smooth muscle relaxants such as nitroglycerine, nitroprusside, hydralazine and diazoxide also produce cerebral vasodilatation with consequent increased $\mathrm{CBF}$ and ICP. ${ }^{34,33}$ Trimetaphan seems to have the least direct effect on the cerebral vasculature. These drugs should be used with caution and where possible, ICP should be monitored.

\section{What is my role in patient management?}

The anaesthetist may be called upon to attend a head-injured patient in four clinical areas of the hospital - the emergency room, the radiology department, the operating room and the intensive case unit. Although the intracranial injuries will vary from mild to severe, the principles of management are the same in all cases. Most head-injured patients are seen by an anaesthetist for non-neurological operative procedures. It cannot be over emphasized that for most patients, it is the scquelae of the brain injury that will limit their return to a normal and useful life.

\section{In the emergency room}

Most head-injured patients that the anacsthctist is asked to see in the emergency room will be semi- or unconscious. As with other medical emergencies, the adequacy of airway, breathing and circulation should be assessed while any available history is obtained. The mouth and nasopharynx should be cleared. All these patients should be treated as if they have a fractured cervical spine until this is disproven. A patent airway should thcrefore be established without undue flexion or extension of the head or neck. If the patient is obtunded enough to need an oral airway, then endotracheal intubation is preferred because of the high incidence of a full stomach (food and/or blood). If the patient is to be transferred to another hospital, an endotracheal tube rather than an airway is mandatory. The intubation should take place, where possible, with the same care and control that would be used with a neurosurgical patient in the operating room. If circumstances and the patient's cardiovascular status 
TABLE I Anaesthesia for head-injured paticnts

\begin{tabular}{l} 
Induction \\
equipment check \\
large bore intravenous \\
preoxygenation \\
\pm d-tubocurarine $0.04 \mathrm{mg} \cdot \mathrm{kg}^{-1}$ \\
sodium thiopentonc or Alfathesin \\
lidocaine $1.5 \mathrm{mg} \cdot \mathrm{kg}^{-1}$ \\
succinylcholine $1-1.5 \mathrm{mg} \cdot \mathrm{kg}^{-1}$ \\
Maintenance \\
Hyperventilation to $\mathrm{PaCO}_{2} 30$ \\
$\mathrm{~N}_{2} \mathrm{O} \mathrm{O}_{2}$ \\
muscle relaxant (pancuronium) \\
narcotic (fentanyl) \\
\pm inhalational agent (isoflurane) or other supplement \\
Monitors \\
EKG \\
BP (arterial line) \\
temperature \\
CVP \\
blood gases \\
urine output \\
\pm ICP \\
\hline
\end{tabular}

For dișeussion see section entilled

"What is my role in patient management?"

allows, the drugs used for induction of anaesthesia should be given prior to intubation (Table I). Oral intubation should be performed by the most experienced person available whilc an assistant applies cricoid pressure. Succinylcholine and thiopentone should be avoided if there is doubt about the ease of intubation lest a serious situation be turned into a fatal one. A nasogastric (or oral gastric) tube should then be inserted. A nasal airway and nasogastric tube should not be used unless one is sure that a basal skull fracture is not present.

Often, once the airway is established, the patient will ventilate adequately or indeed hyperventilate. The apparent adequacy of ventilation should be checked with blood gases. In the severely headinjured patient deliberate hyperventilation to a $\mathrm{PCO}_{2}$ of approximately 30 should be instituted. Some degree of hypoxaemia is almost invariable in patients with severe head injuries. Supplemental oxygen (at least 40 per cent) should always be given on arrival in the emergency room. $\mathrm{PO}_{2}$ should be kept between 80 and $100 \mathrm{mmHg}$.

Establishment of a stable and adequate cardiovascular system is imperative. Hypotension, except as an agonal event, is rarely due to a closed head injury. If hypotension is present, it should be aggressively treated and a source other than the brain injury assiduously sought. Hypertension may occur as an attempt to perfuse an ischaemic brain. As there is also concern that this may result in haemorrhage or oedema formation in vasoparalyzed areas, systolic pressures above 150-170 $\mathrm{mmHg}$ should be treated.

Once the airway, breathing, and circulation (ABC's) are stable, a more detailed history and examination should be documented. The Glasgow coma scale is a simple and consistent scoring system for following neurological function (Table II). This scoring system correlates well with outcome. In addition, brain stem reflexes such as pupillary reaction to light, doll's eyes movements and caloric responses as well as the deep tendon reflexes should be elicited. These should be done prior to administering any anaesthetic, if possible Bilateral fixed and dilated pupils are not synonymous with brain death. Only 85 per cent of headinjured patients with bilateral unreactive pupils will be left dead, vegetative or severely disabled. ' Body temperature should be measured with a low-reading thermometer.

Continual close observation of the patient is important at all times. Changes in vital functions or central nervous system signs may indicate the presence of an expanding mass lesion, brain ischaemia, arousal or the complications of an extracranial injury.

\section{Transport}

No patient should be transported within the hospital or to another hospital without a secure airway, a means of adequate ventilation, a stable cardiovascular system, an intravenous infusion, an empty stomach and appropriate monitoring. The patient should always be accompanied by trained staff and suitable life support systems.

If the patient is to be transported to another hospital, arrangements should be made to inform the admitting team of that facility of the impending arrival so that preparations may be made to take over the patient's care on arrival. A written summary of initial findings and management and any changes en route should accompany the patient. The neurosurgical team at the tertiary centre should also be consulted in regard to the treatment to be given prior to or during transport.

Bucking, straining and restlessness may reflect irritation from the endotracheal tube, the brain 
TABLE II Glascow coma scale

\begin{tabular}{l} 
Eye opening \\
4 Spontaneous \\
3 To speech \\
2 To pain \\
1 None \\
Best verbal response \\
5 Oriented \\
4 Confused \\
3 Inappropriate \\
2 Incomprehensible \\
1 None \\
Best motor response \\
6 Obey commands \\
5 Localizes pain \\
4 Withdraws \\
3 Flexion to pain \\
2 Extension to pain \\
1 None \\
\hline
\end{tabular}

injury, pain or inadequate ventilation. Therapy should be directed at the cause where possible. Small doses of thiopentone, Alfathesin or nondepolarizing neuromuscular blocking drugs may be needed. They all have a salutary effect on ICP

In the radiology department

Anaesthesia in the radiology department presents its own specific problems which may compound the difficulties already faced with the injured patient. The anaesthetist may be asked to see the patient before or during the radiologic procedure. The assessment should be similar to that outlined above. An invitation to "just give him some sedation so that we can get the $x$-rays done" should not be taken lightly. Patient and airway access will almost certainly be extremely difficult once the procedure begins and $C T$ and angiographic studies often require head and neck flexion which may obstruct the airway. Small doses of intravenous analgesics and sedatives may suffice in some, but if any doubt exists about the adequacy of the airway and breathing or the coma scale is less than 12 , the patient should be anaesthetized, intubated and hyperventilated (Table I).

The extra precautions required in the radiology department are due to the lack of the usually available anaesthetic equipment, lack of space, the great distance between the patient and the anaesthetist and the potential complications from angiographic dye and catheters.
All patients should have a chest and cervical spine $x$-ray. The standard supine anterior-posterior chest $x$-rays may not reveal a small or anterior pneumothorax and if possible an erect or lateral decubitus film should be obtained. As well, pulmonary parenchymal disease and mediastinal widening indicative of vascular injury should be looked for. All head-injured patients should be treated as if they have a cervical spine injury until all seven vertebrae have been clearly seen. The neck views may also reveal air collections resulting from laryngeal or tracheal trauma.

\section{In the operating room}

Patients with head injuries may require operative treatment solely for the neurological injuries or for other injuries. All patients who have had any degree of head trauma should be treated as if they have a brain injury.

If the head injury was mild and the patient is awake and coherent, a regional or local technique, if appropriate, may be used. In all other cases, a carcful anaesthetic with intubation and moderate hyperventilation should be employed (Table I). A technique of spontaneous ventilation with inhalation agents has no place in this situation. Although nitrous oxide has been reported to increase ICP, we believe it to be safe in most hyperventilated patients (except severely injured). Pancuronium bromide is the most suitable muscle relaxant but should be titrated slowly to avoid tachycardia and hypertension. Supplemental anaesthesia may be obtained with narcotics, or low concentrations of inhalation agents or other agents (Table I). In the severely head injured, boluses or an infusion of thiopentone or Alfathesin may be a beneficial supplement to the narcotic. Even the unconscious patient should receive an anaesthetic because it reduces $\mathrm{CMRO}_{2}$ and the sympathetic response to surgery. The "oxygen-Pavulon only" technique should be avoided.

In the severely head-injured or haemodynamically unstable patient, in addition to routine monitors, intra-arterial and CVP monitoring is used. Patients receiving Mannitol should have a urinary catheter placed. ICP monitoring allows one to see the need for and effects of therapy and anaesthesia on intracranial dynamics. If the pressure is high $(>15$ $20 \mathrm{mmHg}$ ), then CSF may be drained off, $\mathrm{PaCO}_{2}$ lowered, and Mannitol or thiopentone given until ICP is reduced. 
Patients going to the ICU for further treatment need not have the muscle relaxant reversed at the end of surgery. The other patients should have the anaesthetic discontinued and the muscle relaxant reversed. When the patient is awake, able to maintain and protect his airway, extubation may be effected. If there is any doubt, it is better to err on the side of safety and keep the patient intubated and ventilated. All patients should receive oxygen and be examined neurologically in the recovery room.

\section{In the ICU}

The management of the head-injured patient in the ICU follows the same principles and practices used in the pre- and intraoperative periods.

The patient's ability to maintain as well as protect his airway must be assessed. Most anaesthetists are able to assess the ability to maintain an unobstructed airway but evaluation of the ability to protect the airway is more difficult. We have found the barium swallow very helpful. Ten $\mathrm{ml}$ of barium is syringed into the mouth of the unintubated patient and a chest $x$-ray is taken 15 minutes later. Dye in the tracheobronchial tree is an indication for intubation. Patients who come from the operating room with red rubber or flexometallic tubes in place should have these changed for plastic endotracheal tubes. This should be performed in the same manner as with an elective neurosurgical patient (Table I).

Coughing, straining, suctioning and shivering may all increase ICP. Simple sedation with diazepam, a narcotic or a barbiturate may attenuate this response. Lidocaine $1-1.5 \mathrm{mg} \cdot \mathrm{kg}^{-1}$ and manual hyperventilation before suctioning are also helpful. If the haemodynamic and ICP responses persist, boluses or a continuous infusion of thiopentone or Alfathesin are used to bring the ICP under control. Nondepolarizing neuromuscular blocking drugs may also be needed while propranolol (up to $0.2 \mathrm{mg} \cdot \mathrm{kg}^{-1} \mathrm{IV}$ ) is effective in blocking the haemodynamic response.

The use of controlled hyperventilation is a useful adjunct in the management of head injuries. ${ }^{36}$ The beneficial effects may be due to: 1 . The reduction in ICP from the lower blood flow induced in the uninjured cerebral areas. 2. An inverse steal mechanism whereby blood from healthy brain is shunted to vasoparalyzed ischaemic zones. 3 . The respiratory alkalosis combats the regional cerebral acidosis that interferes with neuronal function and auto- regulation. 4 . The mechanical ventilation usually ensures good oxygenation. We aim to keep the $\mathrm{PCO}_{2}$ between 25 and $30 \mathrm{mmHg}$. This therapy should be continued for at least 24 to 48 hours after the neurological status has been stable. Although normal brain will, with time, return the $\mathrm{CSF}$ pH and thereby $\mathrm{CBF}$ back to normal even in the presence of continued hyperventilation, this may not be the case in the brain that has ongoing tissue acicosis.

Weaning from the respirator should be done cautiously. Some individuals continue to hyperventilate after weaning and then gradually readjust their $\mathrm{PCO}_{2}$ back to normal, while others have dramatic increases in $\mathrm{PCO}_{2}$ on weaning. As there is no way to predict who will fall into which category or at what point in the weaning process a large change in $\mathrm{CO}_{2}$ will occur, all patients require close monitoring during and for at least 48 hours after weaning.

Hypoxaemia should be vigorously treated and $\mathrm{PaO}_{2}$ should be maintained between $80-100$ $\mathrm{mmHg}$. Although increases in intrathoracic pressure may elevate ICP, with the patient 30 degrees head up, up to $10 \mathrm{~cm} \mathrm{H}_{2} \mathrm{O}$ of PEEP is usually well tolerated. In patients with pulmonary contusions or oedema who require the PEEP, the poor pulmonary compliance will prevent much of the airway pressure from being transmitted to the veins.

Therapeutic barbiturate coma has received much attention recently and still remains controversial. ${ }^{21}$ Recent evidence suggests that barbiturates may improve the outcome in those with uncontrollable ICP where an intracranial mass has been excluded and there has been no response to conventional therapy. ${ }^{37}$ Meticulous monitoring is required here. Intra-arterial pressure, CVP and ICP should be monitored continuously and the patient should be ventilated. The barbiturate (thiopentone or pentobarbitone) infusion and boluses are titrated against the ICP rather than to specific blood levels or EEG changes. Complications including hypotension, pulmonary infections, hypothermia and prolonged coma, are not infrequent.

Seizures occur in the first week in five per cent of patients with an injury requiring hospital admission. ICP may be increased due to the associated hypoxia, hypercapnia, acidosis, or raised venous pressure. Increases in $\mathrm{CMRO}_{2}$ occur which will cause ischaemia in regions with marginal blood fiow. Fits are usually treated with intravenous 
diazepam, Dilantin and phenobarbitone. If status epilipticus develops, we prefer to use thiopentone rather than large boluses or an infusion of diazepam because of thiopentone's beneficial effect on ICP. A muscle relaxant may be needed to help secure the airway and stop muscle movement which can produce profound lactic acidosis.

\section{Conclusion}

The anaesthetist has a vital role to play in the management of the head-injured patient. If the primary injury was insufficient to cause death, then theoretically in many cases, avoidance or treatment of the secondary insults should result in a good $r$ utcome. Pivotal to the management of the secondary injury is the management of the airway, breathing and circulation, all areas of expertise for the anaesthetist. With a knowledge of pathophysiology, pharmacology and the necessary technica skills, the anaesthetist should be actively involved in all phases of the patients' acute care.

\section{References}

1 Becker DP, Miller JD, Ward JD, Greenberg RP, Young $H F$, Sakalas $R$. The outcome from severe head injury with early diagnosis and intensive management. J Neurosurg 1977; 47: 491-502.

2 Rose $J$, Valtonen $S$, Jennett $B$. Avoidable factors contributing to death after head injury. $\mathrm{Br}$ Med J $1977 ; 2: 615-8$.

3 Morgan $R W$. Prevention in Clinical Practice. Toronto: University of Toronto Press, 1976.

4 Horton $J M$. The anaesthetist's contribution to the care of head injuries. Br J Anaesth 1976; 48: 767-71.

5 Jennett B. Teasdale, G. Management of Head Injuries. Philadelphia: F.A. Davis Company, 1981.

6 Adams $H$, Mitchell DE, Graham DI, Doyle D. Diffuse brain damage of immediate impact type. Its relationship to "primary brain-stem damage" in head injury Brain 1977; 100; 489-502.

7 Strich SJ. Lesions in the cerebral hemispheres after blunt head injury. J Clin Path 1970, (Suppl, 4); 23: 166-71.

8 Oppenheimer DR. Microscopic lesions in the brain following head injury. J Neurol Neurosurg Psychiat 1968; 31: 299-306.

9 Kety SS, Schmidt CF. The effects of altered arterial tensions of carbon dioxide and oxygen on cerebral blood flaw and cerebral oxygen consumption of nor- mal young men. J Clin Invest 1948; 27: 484-92.

10 Grubb RL, Raichle ME, Eichling JO, Ter-Pogossian $M M$. The cffects of changes in $\mathrm{PaCO}_{2}$ on ccrebral blood volume, blood flow, and vascular mean transit time. Stroke 1974; 5: 630-9.

11 Lassen NA. Cerebral blood flow and oxygen consumption. Physiological Review 1959; 39: 183-93.

12 Sirandgaard S, Olesen $J$, Skinhoj E, Lassen NA. Autoregulation of brain circulation in severe arterial hypertension. Br Med J 1973; 1: 507-10.

13 Overgaard J, Tweed WA. Cerebral circulation after head injury, Part 1: Cerebral blood flow and its regulation after closed head injury with emphasis on clinical correlations. J Neurosurg 1974; 41: 531-41.

14 Cold GE, Jensen FT. Cerebral autoregulation in unconscious patients with brain injury. Acta Anaesthesiol Scand 1978; 22: 270-80,

15 Saunders $M L$, Miller $I D$, Stablein $D$, Allen $G$. The effects of graded experimental trauma on cerebral blood flow and responsiveness to $\mathrm{CO}_{2}$. $\mathrm{J}$ Neurosurg 1979; 51: 18-26.

16 Cotev $S$, Shalit $M N$. Effects of diazepam on cerebral blood and oxygen uptake after head injury. Anesthesiology 1975; 43: 117-22.

17 Smith AL, Wollman $H$. Cerebral blood flow and metabolism: Effects of anesthetic drugs and techniques. Anesthesiology 1972; 36: 378-400.

18 Artru AA, Michenfelder JD. Anoxic cerebral potassium accumulation reduced by phenytoin: Mechanism of cerebral protection? Anesth Analg 1981 ; 60: 41-5.

19 Jobes DR, Kennell E, Bitner R, Swenson E, Wollman $H$. Effects of morphine-nitrous cxide anesthesia on cerebral autoregulation. Anesthesiology $1975 ; 42: 30-4$.

20 Fadden Al. Neuropeptides and stroke: Current status and potential application. Stroke 1983; 14: 169-72.

21 Frost EAM. Brain Preservation. Anesth Analg 1981; 60: 821-32.

22 Pickerodt VWA, McDowall DG, Coroneos NJ, Keaney NP. Effect of althesin on cerebral perfusion, cerebral metabolism and intracranial pressure in the anaesthetized baboon. Br $J$ Anaesth 1972; 44: 751-7.

23 Moss E, Powell D, Gibson RM, McDowall DG. Effects of tracheal intubation on intracranial pressure following induction of anaesthesia with thiopentone or althesin in patients undergoing neurosurgery. Br J Anaesth 1978; 50; 353-60.

24 Takeshita $H, O k u d a Y$, Sari $A$. The effects of keta- 
mine on cerebral circulation and metabolism in man. Anesthesiology 1972; 36: 69-75.

25 Hamill JF, Bedford RF, Weaver DC, Colohan AR. Lidocaine before endotracheal intubation: Intravenous or laryngotracheal? Anesthesiology 1981; 55: 578-81.

26. Bedford RF, Persing JA, Pobereskin L, Butler A. Lidocaine or thiopental for rapid control of intracranial hypertension? Anesth Analg 1980; 59: 435-7.

27 Lassen NA, Tweed WA. Anaesthesia and cerebral blood flow. In E. Gordon (Ed.), Excerpla Medica - New York. 4: 113-33, 1975.

28 Adams RW, Gronert GA, Sundt TM, Michenfelder $J D$. Halothane, hypocapnia, and cerebrospinal fluid pressure in neurosurgery. Anesthesiology. $1972 ; 37: 510-7$.

29 Adams RW, Cucchiara RF, Gronert GA, Messick $J M$, Michenfelder $J D$. Isoflurane and cerebrospinal luid pressure in neurosurgical patients. Anesthesiology 1981; 54: 97-9.

30 Marsh ML, Dunlop BJ. Shapiro HM, Gagnon RL, Rockoff $M A$. Succinylcholine-intracranial pressure effects in neurosurgical patients. Anesth Analg 1980; 59: 550-1.

31 Wilkinson HA, Wepsic JG, Austen G. Diurectic synergy in the treatment of acute experimental cerebral edema. J Neurosurg 1971; 34: 203-8.

32 Gudeman $S K$, Miller $J D$, Becker DP. Failure of high-dose steroid therapy to influence intracranial pressure in patients with severe head injury. $J$ Neurosurg 1979; 51: 301-6.

33 Saul TG, Ducker TB, Saloman M, Carro E. Steroids in severe head injury. A prospective randomized clinical trial. J Neurosurg 1981; 54: 596-600.

34 Turner JM, Powell D, Gibson RM, McDowall $D G$. Intracranial pressure changes in neurosurgical patients during hypotension induced with sodium nitroprusside or trimetaphan. $\mathrm{Br} \mathrm{J}$ Anaesth 1977; 49: 419-25.

35 Overgaard $J$, Skinhoj $E$. A paradoxical cerebral hemodynamic effect of hydralazine. Stroke 1975; 6: $402-4$.
36 Gordon $E$. Controlled respiration in the management of patients with traumatic brain injuries. Acta Anaesthesiol Scand 1971; 15: 193-208.

37 Marshall LF. Smith RW, Shapiro HM. The outcome with aggressive treatment in severe head injurics. Part II: Acute chronic barbiturate administration in the management of head injury. J Neurosurg 1979; 50: $26-30$. 